(1)

CrossMark

\title{
Tuberculosis in the time of COVID-19: quality of life and digital innovation
}

\author{
Dina Visca $\mathbb{1}^{1,2}$, Simon Tiberi $\mathbb{1}^{3,4}$, Emanuele Pontali ${ }^{5}$, Antonio Spanevello ${ }^{1,2}$ \\ and Giovanni Battista Migliori $\mathbb{1}^{6}$
}

Affiliations: ${ }^{1}$ Division of Pulmonary Rehabilitation, Istituti Clinici Scientifici Maugeri, IRCCS, Tradate, Italy. ${ }^{2}$ Dept of Medicine and Surgery, Respiratory Diseases, University of Insubria, Tradate, Italy. ${ }^{3}$ Dept of Infection, Royal London and Newham University Hospitals, Barts Health NHS Trust, London UK. ${ }^{4}$ Blizard Institute, Barts and the London School of Medicine and Dentistry, Queen Mary University of London, London UK. ${ }^{5}$ Dept of Infectious Diseases, Galliera Hospital, Genoa, Italy. 'SServizio di Epidemiologia Clinica delle Malattie Respiratorie, Istituti Clinici Scientifici Maugeri IRCCS, Tradate, Italy.

Correspondence: Giovanni Battista Migliori, Servizio di Epidemiologia Clinica delle Malattie Respiratorie Istituti Clinici Scientifici Maugeri IRCCS, Via Roncaccio 16, Tradate, Varese, 21049, Italy. E-mail: giovannibattista.miglioridicsmaugeri.it

@ERSpublications

COVID-19 affects healthy individuals, patients and healthcare professionals, as well as tuberculosis services. The importance of digital technologies and the impact on quality of life are discussed. https:// bit.ly/2U8nA0h

Cite this article as: Visca D, Tiberi S, Pontali E, et al. Tuberculosis in the time of COVID-19: quality of life and digital innovation. Eur Respir J 2020; 56: 2001998 [https://doi.org/10.1183/13993003.01998-2020].

\section{Introduction: the COVID-19 "storm" on individuals, patients and healthcare} professionals

The year 2020 will be remembered as the year coronavirus disease 2019 (COVID-19) swept the world and overwhelmed healthcare systems, demonstrating several vulnerabilities and a lack of capacity.

The COVID-19 "storm" has created much damage and will hopefully end (with or without secondary waves, we do not yet know), leaving us in an aftermath with numerous challenges for those involved (table 1$)[1,2]$.

COVID-19 has had a severe impact on a number of parties. For healthy individuals, there has been the worldwide implementation of social distancing measures, lockdown, an unprecedented economic crisis with resultant unemployment, and a feeling of not knowing when it will end. This has generated anxiety and an increase in mental health issues, and in some cases has led to suicide.

With regard to patients, numbers have varied globally, with increased mortality amongst the elderly and patients with pre-existing comorbidities. The socioeconomic consequences of the storm are contributing to increased poverty, deprivation, isolation, malnutrition and related morbidity and mortality [3].

And for healthcare professionals, the situation has been a nightmare: the request to focus on COVID-19 as a priority; redistribution of healthcare workers into clinical duties; devoting all their energy to preventing, diagnosing and treating this new disease, with limited possibilities to rest and enjoy their family. All this whilst observing an unprecedented pressure on the health system and seeing many colleagues admitted (3.8\% in China, $6 \%$ in the UK, $10 \%$ in Spain) and, unfortunately, dying.

A common occurrence that has been the subject of debate in several medical journals is the rapid reorganisation of health systems to tackle the COVID-19 pandemic by increasing the number of intensive 
TABLE 1 The challenges and changes facing healthcare staff and patients during the coronavirus disease 2019 (COVID-19) epidemic

\section{Lockdown}

\section{Social distancing}

\section{Differential diagnosis}

\section{Avoiding transmission of SARS-CoV-2 in healthcare settings}

\section{Peaks of epidemic}

Loss of work, loss of income

Increase in mental health issues, domestic violence and suicide

Everyone

Limited options for transportation to healthcare facilities

Aggression and racism towards minorities

Cancellation of appointments and elective surgery

Reduced or no access to hospital to visit loved ones

Reduced or no access to funerals and religious ceremonies

Less attention/reduced priority for comorbidities and other diseases (i.e. avoiding accessing healthcare facilities due to fear, even in the presence of severe symptoms)

Personal drug procurement: reduced access to pharmacies, especially hospital pharmacies and public dispensaries

Drug distribution irregularities

Nursery and school closures

Cancellation of exams, lost school years

Cancellation of holidays

Reduction in support from peers, social workers, relatives, friends

Everyone

Increased isolation and deprivation

Travel challenges: disruption to public transport, fewer seats available, booking necessary (even for short-to-medium distances)

Long queues for shopping essentials

Increase in mental health issues, domestic violence and suicide

Increase in number and type of diagnostic procedures and tests (to exclude or confirm concomitant COVID-19]

Reduction in spirometry, imaging and ultrasonography due to infection-control concerns Lack of reagents due to unprecendented global demand

Lack of laboratory capacity

Reduced medical workforce due to illness

Misdiagnosis, especially of respiratory comorbidities (at least during COVID-19 peaks)

Delayed diagnosis

Underestimation of the clinical impact of concomitant comorbidities (respiratory or not)

Challenges in diagnosis of COVID-19 versus TB sequelae

Reduction in number of patients evaluated per day (more time needed to assess patients)

Changes in flow for diagnosis and visits within health facilities

Slower procedures: triage pre-entry; disinfection after each visit/diagnostic procedure; personal distancing (from a patient to another or from patient to health staff), etc.

Postponing appointments (at least during COVID-19 peaks)

Temporary discontinuation of rehabilitation activities (at least during COVID-19 peaks)

Limiting outpatient activities to urgent issues (at least during COVID-19 peaks)

Replacement of face-to-face activities with phone/remote web-based interactions (including psychological support, adherence support initiatives, etc.)

Lack of protective equipment (at least during COVID peaks)

Increased cost of healthcare services

Shift of resources (financial, staff, protective equipment, laboratory, other diagnostics, etc.) from existing programmes to COVID-19

Paralysis of emergency departments (at least during COVID-19 peaks)

Shift of HCWs to COVID-19 wards

High transmission of SARS-CoV-2 to HCWs: sick leave, HCW hospitalisations, HCW deaths

Health staff for contact tracing activities shifted to COVID-19

Rapid exhaustion of protective equipment (at least during COVID-19 peaks)

Lack of drugs, oxygen, consumables

Lack of invasive and noninvasive ventilators
Patients

HCWs

Patients HCWs

Patients HCWs

HCWs: healthcare workers; TB: tuberculosis; SARS-CoV-2: severe acute respiratory syndrome coronavirus 2. 
care unit (ICU) beds [4], and reducing/cancelling out-patient activities and non-urgent clinical activities (e.g. screening and follow-up activities, elective surgery, etc.). Another important shift was to substitute, in whichever way possible, clinical examinations and "in person" meetings with phone consultations and web-based activities [5].

In many countries, pulmonologists, and infectious disease and public health experts (those also involved in tuberculosis (TB) prevention and care) together with ICU specialists are or have been re-deployed to the frontline to fight COVID-19 [5].

\section{COVID-19 and TB services}

A modelling analysis commissioned by the STOP TB Partnership (Geneva, Switzerland) has indicated that the COVID-19 pandemic is deeply affecting the efforts of TB services in prevention, case detection and management [6]. This is particularly evident in resource-limited settings, but can also be seen to varying degrees in resource-rich settings [6]. As a result, an increase in TB incidence and mortality is expected in the future, potentially compromising the results achieved so far and delaying the End TB Strategy timelines [6].

Discussion about the association between COVID-19 and TB is ongoing. Analysis of two cohorts of co-infected patients has shown that COVID-19 can appear before, simultaneously or after TB (and this includes patients with post-TB treatment sequelae) [7-9] and that mortality is higher amongst elderly TB patients with pre-existing comorbidities [9].

Two interesting topics are generating a great deal of scientific debate: the effects of TB on the quality of life (QoL) of TB patients with or without COVID-19 before, during and after anti-TB treatment (with the need for pulmonary rehabilitation); and the potential offered by web-based approaches to TB management [10].

We aim to discuss these two areas by presenting two articles that appear in this issue of the European Respiratory Journal (ERJ) [11, 12], and by making a rapid review of the evidence available on TB, QoL and TB rehabilitation in the literature by searching on Medline, as well as in the grey literature. The keywords "quality of life", "pulmonary rehabilitation" and "tuberculosis" were used without any time limits.

\section{TB, QoL and pulmonary rehabilitation}

51 records were identified, including a review focused on the effectiveness of pulmonary rehabilitation in patients with post-treatment sequelae [13], five original articles [14-18] and one case report [19], reporting both pre- and post-TB rehabilitation information for at least one core examination (i.e. spirometry, walking test, QoL tests) [14-20]. The studies all reported in English, were conducted in four continents (Africa, Asia, Europe and Latin America) with a small sample size (1-64 patients) and 50\% of them were on an in-patient basis. The 6-min walking test (6MWT) or equivalent was conducted in all studies, as well as QoL tests. The mean distance covered with the 6MWT was significantly higher after pulmonary rehabilitation, ranging $11-110 \mathrm{~m}$.

Spirometry was conducted in five studies and demonstrated improvement in the core spirometry parameters (forced expiratory volume in $1 \mathrm{~s}$ and forced vital capacity) after pulmonary rehabilitation, although age and smoking habits differed in the studies.

Among the main messages of the existing review [13], we underline: 1) the high proportion of patients with post-TB treatment sequelae with a limited capacity to perform exercise and a poor QoL; 2) the effectiveness of pulmonary rehabilitation in improving walking distance (6MWT), the QoL assessment and core spirometry parameters; and 3) the need for further research [20].

The importance of QoL in TB has increased over time. According to the World Health Organization (WHO), health is "a state of complete physical, mental, and social wellbeing and not merely the absence of disease or infirmity" [21].

Therefore, QoL has a precise role in the WHO-recommended vision of "people-centred care", which is built in to the End TB Strategy [22].

The traditional vision of national TB programmes focused on improving treatment success rates more than on individual post-treatment wellbeing, largely due to historical funding constraints [14, 23]. In recent years, and before the COVID-19 pandemic, more and more countries (beginning with Brazil, Russia, South Africa and other intermediate-income countries) have shown an interest in rehabilitation for post-treatment sequelae due to increased access to funding and technology [23].

Among the different QoL tools reported in the literature [24], there are generic questionnaires such as the 36-item Short-Form Health Survey (SF-36) and its shortened version with 12 questions, or specific tools 
such as the St Georges's Respiratory Questionnaire that are specifically used to investigate QoL in chronic respiratory diseases (tables 2 and 3).

\section{QoL, treatment outcomes and the EUROHIS-QOL questionnaire}

Amongst the available questionnaires, the EuroQol 5 Dimensions and the SF-36, which are used to calculate quality adjusted life years have been also used in TB $[25,26]$. Unfortunately, they cannot capture the economic and social "areas" that are important for $\mathrm{TB}$, given its relationship with poverty and isolation.

The WHO QoL group developed a 100-item questionnaire able to capture different QoL aspects in different cultural environments and with different languages. Shorter versions were also developed for operational research and clinical use, such as the 24-question WHOQOL-BREF and the eight-question EUROHIS-QOL questionnaire [27]. Both tools assess the four QoL core dimensions that are relevant for TB patients: physical health, psychological health, social interactions and satisfaction with living conditions, including economic QoL [27-31]. The EUROHIS-QOL is a brief questionnaire with the potential of retaining the psychometric properties of WHOQOL-BREF; however, it has only been used to evaluate QoL in a few conditions [32].

In this issue of the ERJ, DATTA et al. [11] report on QoL and treatment outcomes in a case-control, nested cohort of patients. The study was performed in different settings (rural and urban) in Peru and involved: 1545 patients, these were individuals $>15$ years of age who were initiating anti-TB treatment in community health centres; 3180 "contacts", these were individuals who reported sharing a patient's household for $>6 \mathrm{~h}$ per week in the 2 weeks preceding the patient commencing anti-TB treatment; and 277 "controls", individuals who were randomly selected from within the same communities. The sample size, evaluated post hoc, ensured $>90 \%$ power at the $95 \%$ significance level to detect a 4 -point QoL score difference in patients versus controls, and a 1-point difference in contacts versus controls.

The study results indicate that the EUROHIS-QOL eight-item questionnaire is a valid instrument to measure general QoL in TB patients. The vast majority of patients completed it, showing that the questionnaire is reliable and therefore a valid tool to evaluate QoL in these patients. Importantly, patients with TB (and especially multidrug-resistant (MDR)-TB) had lower QoL than community controls as far as TB symptoms and psychosocial QoL dimensions were concerned. TB patients with lower QoL at diagnosis were less likely to complete their TB treatment cycle and survive. The study also allowed for the evaluation of QoL among the patient's household contacts.

This study shows that programmatic QoL evaluation is feasible and can be conducted with simplified tools to improve the outcomes of TB and MDR-TB treatment.

\section{Adherence and e-health}

Adherence is a core component of TB treatment, as the traditional dogma of TB control is that rapid and effective treatment is the best preventive measure to reduce infectiousness and break the chain of transmission within the community [33].

From this perspective, good adherence is key to ensuring a high success rate at the end of treatment, and directly observed therapy (DOT) or its electronic version, video-observed therapy (VOT), are important tools to supporting this.

In this issue of the ERJ, RAVENSCROFT et al. [12] evaluate the effectiveness of VOT for the first time in lowand middle-income countries. The authors evaluated the effectiveness and patient cost-difference of VOT by comparing VOT with clinic-based DOT in Moldova. The study was designed as a two-arm randomised trial, including 98 cases (VOT group) and 99 controls (DOT group) with observed medication adherence (measured by the number of days per 2 -week period that a patient failed to be observed taking medication).

The authors found that VOT significantly decreased non-adherence by 4 days per 2-week period (5.24 days missed per 2-week period for DOT and 1.29 for VOT). From an economic perspective, VOT patients spent approximately $€ 25$ and $58 \mathrm{~h}$ less on their treatment than DOT patients. As in the majority of DOT studies, no significant improvements were seen amongst VOT patients with regard to treatment success, patient wellbeing or patient employment status.

The main messages of this study are: VOT is feasible in an Eastern European setting, it saves patients' time and money and increases satisfaction. These results are useful and justify larger studies (the sample size was relatively small) that evaluate programmatic feasibility. This is even more relevant in the context of the COVID-19 pandemic, when the prevention of transmission and the need to focus on essential services has reduced the volume of outpatient activities. This, unfortunately, is affecting TB activities in several countries. An additional important result is the increase in the reporting of adverse events. This needs to 
TABLE 2 Generic tools to evaluate health-related quality of life (HRQoL) in chronic respiratory diseases

\begin{tabular}{|c|c|c|c|c|c|}
\hline Questionnaire & $\begin{array}{c}\text { Items } \\
\mathrm{n}\end{array}$ & Domains & $\begin{array}{l}\text { Administration } \\
\text { time }\end{array}$ & $\begin{array}{l}\text { Mode of } \\
\text { administration }\end{array}$ & Score \\
\hline $\begin{array}{l}\text { World Health Organization } \\
\text { Quality of Life questionnaire } \\
\text { WHOQOL-100 }\end{array}$ & 100 & $\begin{array}{l}\text { Physical health } \\
\text { Psychological } \\
\text { Level of independence } \\
\text { Social relationships } \\
\text { Environment } \\
\text { Spiritual/religious/personal } \\
\text { beliefs }\end{array}$ & $30 \mathrm{~min}$ & Self-administered & $\begin{array}{l}\text { Scores available for domains, facets and overall } \\
\text { Higher scores indicate better HRQoL } \#\end{array}$ \\
\hline $\begin{array}{l}\text { World Health Organization } \\
\text { Quality of Life questionnaire } \\
\text { WHOQOL-BREF }\end{array}$ & 26 & $\begin{array}{l}\text { Physical health } \\
\text { Psychological } \\
\text { Social relationships } \\
\text { Environment }\end{array}$ & $10-15 \min$ & Self-administered & $\begin{array}{l}\text { Items answered using individualised five-point scales } \\
\text { Each subscale is scored positively } \\
\text { Higher scores indicate better HRQoL }\end{array}$ \\
\hline EUROHIS-QOL & 8 & $\begin{array}{l}\text { Physical health } \\
\text { Psychological } \\
\text { Social relationships } \\
\text { Environment }\end{array}$ & $10 \mathrm{~min}$ & Self-administered & $\begin{array}{l}\text { Items answered using individualised five-point scales } \\
\text { Each subscale is scored positively } \\
0-32 \text {; higher scores indicate better HRQoL }\end{array}$ \\
\hline $\begin{array}{l}\text { The } 36 \text {-item Short Form Health } \\
\text { Survey (SF-36v2) }\end{array}$ & 36 & $\begin{array}{l}\text { Vitality } \\
\text { Physical functioning } \\
\text { Bodily pain } \\
\text { General health perceptions } \\
\text { Physical role functioning } \\
\text { Emotional role functioning } \\
\text { Social role functioning } \\
\text { Mental health }\end{array}$ & $\begin{array}{l}\text { Mean } \pm S D \\
10 \pm 8 \text { min }\end{array}$ & Self-administered & $\begin{array}{l}\text { Higher scores indicate better HRQoL } \\
\text { The correct calculation of SF- } 36 \text { requires the use of special } \\
\text { algorithms, which are strictly controlled by a private } \\
\text { company" }\end{array}$ \\
\hline EuroQol 5 Dimensions (EQ-5D) & 5 & $\begin{array}{l}\text { Mobility } \\
\text { Self-care } \\
\text { Usual activities } \\
\text { Pain/discomfort } \\
\text { Anxiety/depression } \\
\text { Additional perceived health } \\
\quad \text { status measured using a VAS }\end{array}$ & $5-10 \mathrm{~min}$ & Self-administered & $\begin{array}{l}\text { Two scores, one for the five domains and another for the } \\
\text { VAS } \\
\text { The five domains score 1-3; higher scores indicate worse } \\
\text { HRQoL } \\
\text { VAS score 0-100; higher scores indicate better HRQoL }\end{array}$ \\
\hline Nottingham Health Profile (NHP) & 38 & $\begin{array}{l}\text { Physical mobility } \\
\text { Pain } \\
\text { Social isolation } \\
\text { Emotional reactions } \\
\text { Energy } \\
\text { Sleep }\end{array}$ & $5-10 \mathrm{~min}$ & Self-administered & 0-100; higher scores indicate worse HRQoL \\
\hline
\end{tabular}


TABLE 3 Tools to evaluate health-related quality of life (HRQoL) for specific chronic respiratory diseases

\begin{tabular}{|c|c|c|c|c|c|c|}
\hline Questionnaire & $\begin{array}{l}\text { Respiratory } \\
\text { disease }\end{array}$ & $\begin{array}{c}\text { Items } \\
\mathrm{n}\end{array}$ & Domains & $\begin{array}{l}\text { Administration } \\
\text { time }\end{array}$ & Mode of administration & Score \\
\hline $\begin{array}{l}\text { Functional Assessment of Chronic Illness } \\
\text { Therapy } \\
\text { (FACIT-TB) }\end{array}$ & TB & 47 & $\begin{array}{l}\text { Physical wellbeing } \\
\text { Psychological wellbeing } \\
\text { Function wellbeing } \\
\text { Social wellbeing } \\
\text { Spiritual wellbeing } \\
\text { Environment } \\
\text { Perception }\end{array}$ & $\begin{array}{l}\text { Mean } \pm \text { SD } 16.3 \\
\pm 3.1 \mathrm{~min}\end{array}$ & Self-administered & $\begin{array}{l}\text { 0-180; higher } \\
\text { scores indicate } \\
\text { better HRQoL }\end{array}$ \\
\hline $\begin{array}{l}\text { Pulmonary Tuberculosis Scale of the System } \\
\text { of Quality of Life Instruments for Chronic } \\
\text { Diseases (QLICD-PT) }\end{array}$ & Tuberculosis & 40 & $\begin{array}{l}\text { Physical domain } \\
\text { Psychological domain } \\
\text { Social domain } \\
\text { TB-specific domain }\end{array}$ & $\sim 10$ min & Self-administered & $0-100$ \\
\hline $\begin{array}{l}\text { St George's Respiratory Questionnaire } \\
\text { (SGRQ) }\end{array}$ & $\begin{array}{l}\text { Asthma and } \\
\text { COPD }\end{array}$ & 76 & $\begin{array}{l}\text { Symptoms } \\
\text { Activity } \\
\text { Impacts }\end{array}$ & $15 / 20 \min$ & Self-administered & $\begin{array}{l}\text { 0-100; higher } \\
\text { scores indicate } \\
\text { worse HRQoL }\end{array}$ \\
\hline $\begin{array}{l}\text { Maugeri Respiratory Failure Questionnaire } \\
\text { (MRF-28) }\end{array}$ & $\begin{array}{l}\text { Chronic } \\
\text { respiratory failure }\end{array}$ & 28 & $\begin{array}{l}\text { Daily activities } \\
\text { Cognition } \\
\text { Invalidity, and additional items } \\
\text { related to fatigue, depression and } \\
\text { problems with treatment }\end{array}$ & $\begin{array}{l}\text { Mean } \pm \text { SD } \\
15 \pm 6 \text { min }\end{array}$ & Self-administered & $\begin{array}{l}\text { 0-100; higher } \\
\text { scores indicate } \\
\text { worse HRQoL }\end{array}$ \\
\hline $\begin{array}{l}\text { Chronic Respiratory Disease Questionnaire } \\
\text { (CRQ) }\end{array}$ & $\begin{array}{l}\text { Chronic } \\
\text { respiratory } \\
\text { disease }\end{array}$ & 20 & $\begin{array}{l}\text { Dyspnoea } \\
\text { Fatigue } \\
\text { Emotional function } \\
\text { Mastery of disease }\end{array}$ & $15-25 \min$ & Interviewer-administered & $\begin{array}{l}\text { Numerical, 7-point } \\
\text { modified Likert } \\
\text { Scale } \\
\text { Higher scores } \\
\text { indicate better } \\
\text { HRQoL }\end{array}$ \\
\hline Quality of Life-Bronchiectasis (QOL-B) & $\begin{array}{c}\text { Non-CF } \\
\text { bronchiectasis }\end{array}$ & 37 & $\begin{array}{l}\text { Physical functioning } \\
\text { Role functioning } \\
\text { Vitality } \\
\text { Emotional functioning } \\
\text { Social functioning } \\
\text { Health perceptions } \\
\text { Treatment burden }\end{array}$ & $4-5 \min$ & Self-administered & $\begin{array}{l}0-100 \text {; higher } \\
\text { scores indicate } \\
\text { better HRQoL }\end{array}$ \\
\hline Asthma Quality of Life Questionnaire (AQLQ) & Asthma & 32 & $\begin{array}{l}\text { Symptoms } \\
\text { Activity limitation } \\
\text { Emotional function } \\
\text { Environmental exposure }\end{array}$ & 4-5 min & Self-administered & $\begin{array}{l}\text { 1-7; higher scores } \\
\text { indicate better } \\
\text { HRQoL }\end{array}$ \\
\hline
\end{tabular}

TB: tuberculosis; CF: cystic fibrosis. 
be seen as a positive "effect" of VOT, which allows otherwise unemerging adverse events to be reported, as recommended by WHO [34].

\section{Conclusion}

A lack of staff, protective equipment, tests and drugs are all well known in the management of TB in diverse settings; this has now unfortunately spread to other programmes and systems. COVID-19 will invariably affect the lung health of many and potentially lead to a greater incidence of TB over the coming years. It is already evident that the pandemic has delayed our ambitious End-TB Strategy timelines, so that greater attention and investments will now be needed to control TB.

The rehabilitation and QoL of TB patients is gaining traction as we understand that patients continue to have sequelae beyond TB treatment completion, and more effort is required to improve QoL and raise life expectancy in this group of patients.

COVID-19 is radically changing the way we manage TB in the immediate future and is forcing us to accelerate the adoption of digital innovations that simplify and facilitate the workload of healthcare workers. COVID-19 has also unmasked and laid bare several vulnerabilities already well known in the TB world; innovation and digital technologies will need to be adopted to help us get back on track.

Acknowledgements: The authors wish to thank Rosella Centis and Lia D'Ambrosio for their technical support in drafting the article and for their useful comments on the manuscript.

Conflict of interest: D. Visca has nothing to disclose. S. Tiberi has nothing to disclose. E. Pontali has nothing to disclose. A. Spanevello has nothing to disclose. G.B. Migliori has nothing to disclose.

\section{References}

1 Alagna R, Besozzi G, Codecasa LR, et al. Celebrating World Tuberculosis Day at the time of COVID-19. Eur Respir J 2020; 55: 2000650.

2 Dara M, Sotgiu G, Reichler MR, et al. New diseases and old threats: lessons from tuberculosis for the COVID-19 response. Int J Tuberc Lung Dis 2020; 24: 544-545.

3 Saunders MJ, Evans CA. COVID-19, tuberculosis, and poverty: preventing a perfect storm. Eur Respir J 2020; 56: 2001348.

4 Vitacca M, Nava S, Santus P, et al. Early consensus management for non-ICU ARF SARS-CoV-2 emergency in Italy: from ward to trenches. Eur Respir J 2020; 55: 2000632.

5 Stop TB Partnership (2020). We did a rapid assessment: the TB response is heavily impacted by the COVID-19 pandemic http://www.stoptb.org/news/stories/2020/ns20_014.html Date last accessed: 1 July 2020 Date last updated: 8 April 2020.

6 Stop TB Partnership, Imperial College, Avenir Health, Johns Hopkins University, and USAID. The Potential Impact of the COVID-19 Response on Tuberculosis in High-Burden Countries: A Modelling Analysis. http://www. stoptb.org/assets/documents/news/Modeling\%20Report_1\%20May\%202020_FINAL.pdf Date last updated: 1 May 2020. Date last accessed: 21 May 2020.

7 Tadolini M, Codecasa LR, García-García JM, et al. Active tuberculosis, sequelae and COVID-19 co-infection: first cohort of 49 cases. Eur Respir J 2020; 56: 2001398.

8 Stochino C, Villa S, Zucchi P, et al. Clinical characteristics of COVID-19 and active tuberculosis co-infection in a Italian reference hospital. Eur Respir J 2020; 56: 2001708.

9 Motta I, Centis R, D'Ambrosio L, et al. Tuberculosis, COVID-19 and migrants: preliminary analysis of deaths occurring in 69 patients from two cohorts. Pulmonology 2020; in press [https://doi.org/10.1016/j.pulmoe.2020.05. 002].

10 Ngwatu BK, Nsengiyumva NP, Oxlade O, et al. The impact of digital health technologies on tuberculosis treatment: a systematic review. Eur Respir J 2018; 51: 1701596.

11 Datta S, Gilman RH, Montoya R, et al. Quality of life, tuberculosis and treatment outcome; a case-control and nested cohort study. Eur Respir J 2020; 56: 2000495.

12 Ravenscroft L, Kettle S, Persian R, et al. Video-observed therapy and medication adherence for tuberculosis patients: randomised controlled trial in Moldova. Eur Respir J 2020; 56: 2000493.

13 Visca D, Centis R, D'Ambrosio L, et al. Post-TB treatment pulmonary rehabilitation: do we need more? Int J Tuberc Lung Dis 2020; in press [https://doi.org/10.5588/ijtld.20.0030].

14 Visca D, Zampogna E, Sotgiu G, et al. Pulmonary rehabilitation is effective in patients with tuberculosis pulmonary sequelae. Eur Respir J 2019; 53: 1802184.

15 Singh SK, Naaraayan A, Acharya P, et al. Pulmonary rehabilitation in patients with chronic lung impairment from pulmonary tuberculosis. Cureus 2018; 10: e3664.

16 Jones R, Kirenga BJ, Katagira W, et al. A pre-post intervention study of pulmonary rehabilitation for adults with post-tuberculosis lung disease in Uganda. Int J Chron Obstruct Pulmon Dis 2017; 12: 3533-3539.

17 de Grass D, Manie S, Amosun SL. Effectiveness of a home-based pulmonary rehabilitation programme in pulmonary function and health related quality of life for patients with pulmonary tuberculosis: a pilot study. Afr Health Sci 2014; 14: 866-872.

18 Ando M, Mori A, Esaki H, et al. The effect of pulmonary rehabilitation in patients with post-tuberculosis lung disorder. Chest 2003; 123: 1988-1995.

19 Wilches EC, Rivera JA, Mosquera R, et al. Pulmonary rehabilitation in multi-drug resistant tuberculosis (TB MDR) a case report. Colomb Med 2009; 40: 436-441. 
20 Allwood B, van der Zalm M, Amaral A, et al. Perspectives from the 1st International Post-Tuberculosis Symposium, Stellenbosch, South Africa, 2019. Int J Tuberc Lung Dis 2020; in press [https://doi.org/10.5588/ijtld. 20.0067].

21 World Health Organization. Constitution of the World Health Organization. https:/www.who.int/governance/eb/ who_constitution_en.pdf Date last accessed: 1 July 2020. Date last updated: October 2006.

22 World Health Organization. Ethics guidance for the implementation of the End TB strategy. Geneva, World Health Organization, 2017.

23 Muñoz-Torrico M, Rendon A, Centis R, et al. Is there a rationale for pulmonary rehabilitation following successful chemotherapy for tuberculosis? J Bras Pneumol 2016; 42: 374-385.

24 Visca D, Tiberi S, Centis R, et al. Post-tuberculosis (TB) Treatment: the role of surgery and rehabilitation. Appl Sci 2020; 10: 2734

25 Guo N, Marra F, Marra CA. Measuring health-related quality of life in tuberculosis: a systematic review. Health Qual Life Outcomes 2009; 7: 14

26 Brown J, Capocci S, Smith C, et al. Health status and quality of life in tuberculosis. Int J Infect Dis 2015; 32: 68-75.

27 da Rocha NS, Power MJ, Bushnell DM, et al. The EUROHIS-QOL 8-item index: comparative psychometric properties to its parent WHOQOL-BREF. Value Heal 2012; 15: 449-457.

28 The WHOQOL Group. Development of the World Health Organization WHOQOL-BREF quality of life assessment. The WHOQOL Group. Psychol Med 1998; 28: 551-558.

29 Nosikov A, Gudex C. EUROHIS: developing common instruments for health surveys. https://www.euro.who.int/ data/assets/pdf_file/0015/101193/WA9502003EU.pdf Date last accessed: 21 May 2020.

30 Schmidt S, Mühlan H, Power M. The EUROHIS-QOL 8-item index: psychometric results of a cross-cultural field study. Eur J Public Health 2006; 16: 420-428.

31 Chang B, Wu AW, Hansel NN, et al. Quality of life in tuberculosis: a review of the English language literature. Qual Life Res 2004; 13: 1633-1642.

32 Rocha NS, Power MJ, Bushnell DM, et al. The EUROHIS-QOL 8-item index: comparative psychometric properties to its parent WHOQOL-BREF. Value Heal 2012; 15: 449-457.

33 Migliori GB, Nardell E, Yedilbayev A, et al. Reducing tuberculosis transmission: a consensus document from the World Health Organization Regional Office for Europe. Eur Respir J 2019; 53: 1900391.

34 Borisov S, Danila E, Maryandyshev A, et al. Surveillance of adverse events in the treatment of drug-resistant tuberculosis: first global report. Eur Respir J 2019; 54: 1901522. 